\title{
Design\& In-Vitro Evaluation of Sustained Release Matrix Tablet of Repaglinide
}

\author{
Gaurav Agarwal*, Shagun G, Surrender K and Shilpi A \\ Faculty of Pharmacy \& Faculty of applied Sciences, RPIIT Technical and Medical \\ Campus, India
}

*Corresponding author: Dr. Gaurav Agarwal, Dean, Faculty of Pharmacy, RPIIT
Research Article

Volume 2 Issue 2

Received Date: January 06, 2018

Published Date: June 14, 2018

Technical and Medical Campus, Haryana, India, Tel: +91 7206228592; Email: gbitsian@yahoo.com

\section{Abstract}

The aim of present is to develop \& evaluate Sustained release matrix tablet of Repaglinide. Repaglinide is an effective ant hyperglycemic. But owing to its shorter half life it needs frequent administration In present study, an attempt has been made to develop Sustained release matrix tablet of Repaglinide thereby reducing its frequency of administration \& other dose related side effects. Various grades of HPMC (K4M \& 15M), sodium alginate \& Eudragit L 100 were used as hydrophilic matrix polymer. Croscarmellose was used as swelling agent. Total 12 formulations were prepared in trial batches. The formulations were evaluated for various pre compression \& post compression parameters. All the formulations showed compliance with the pharmacopoeial standards. On the basis of evaluated parameters formulation F6 was considered to be the best one. Formulation F6 containing polymer sodium alginate showed $98.67 \%$ in-vitro drug release profile. The release data for formulation F6 was fitted to various mathematical models like zero order, first order, Krosmeyer Peppas \& Higuchi model. It was observed that drug follows zero order kinetics \& Higuchi model.

Keywords: Repaglinide; Sustained Release Matrix; HPMC (K4M, K15M); Sodium alginate; Eudragit L 100; Croscarmellose; Wet Granulation

\section{Introduction}

Among the innumerable methods used for sustained release formulation matrix is the most popular approach. Hydrophilic or hydrophobic polymers are used as release retardants. Hydrophilic polymers are most widely used in matrix system because these are cost effective, make it easy to achieve desirable drug profile \& have broader FDA acceptance. Drug release through matrix system is governed by water penetration, polymer swelling, drug dissolution \& drug diffusion [1-3]. Diabetes Mellitus is a metabolic disorder resulting from defective insulin secretion, action or both [4]. Repaglinide is an effective ant hyperglycemic used for the management of Type 2 Diabetes Mellitus. It is a benzoic acid derivative belonging to meglitinide class of oral hypoglycemic. After oral administration it is rapidly \& completely absorbed \& peak plasma concentration is achieved in approximately $1 \mathrm{hr}$. It is removed from the blood stream within a span of $1 \mathrm{hr}$. The mean absolute bioavailability is $56 \%$ when given with 
food [5]. Due to its shorter duration of action \& faster onset of action it serves as good candidate for SR matrix tablets [6]. Numerous studies have been reported in the literature regarding the use of hydrophilic polymers like Sodium Alginate, Eudragit L 100, Hydroxyl Propyl Methyl Cellulose (HPMC) to control the release of drug from matrices. Thus, in present study an attempt has been made to formulate sustained release matrix tablet of repaglinide \& to evaluate the same for various parameters; in order to produce additional antidiabetic activity thereby resulting in dose reduction \& its dose related side effects.

\section{Materials and Method}

Repaglinide was obtained as free gift sample from Torrent Pharmaceuticals Limited, Gujarat, India. Sodium Alginate, HPMC K4M, HPMC K15M \& Eudragit L 100 were purchased from yarrow chemicals products, Mumbai. Talc, PVP K30, Magnesium Stearate were purchased from SD Fine chemicals Ltd., Mumbai. Croscarmellose sodium was offered as gift sample from Shreeji pharma International.

\section{Formulation of Sustained Release Matrix Tablets}

Tablet Formulations were prepared using non aqueous solvents by wet granulation method. The compositions of different trial batches so prepared are mentioned in Table1. Different excipients in mentioned proportion were weighed individually and sifted through sieve no. 60. Half of the required quantity of all ingredients excluding Magnesium stearate and talc were mixed together for about 15 minutes. For the purpose of wet granulation of final blend PVP K30 dissolved in Iso Propyl Alcohol was used. The damp wet mass prepared in mortar and was passed through sieve no. 12. The granules so prepared were dried in hot air oven at $60{ }^{\circ} \mathrm{C}$ for 30 minutes. The dried granules were passed through sieve no. 16. Then rest half quantity of the ingredients were added and mixed in the granules. The blend was then lubricated with Magnesium stearate and talc. Finally tablets were compressed to net weight of $200 \mathrm{mg}$ by using 10 station mini rotary tablet punching machine.

\begin{tabular}{|c|c|c|c|c|c|c|c|c|c|c|c|c|}
\hline \multirow{2}{*}{ Ingredients } & \multicolumn{9}{|c|}{ Formulation Code (in mg) } \\
\cline { 2 - 14 } & F1 & F2 & F3 & F4 & F5 & F6 & F7 & F8 & F9 & F10 & F11 & F12 \\
\hline Repaglinide & 10 & 10 & 10 & 10 & 10 & 10 & 10 & 10 & 10 & 10 & 10 & 10 \\
\hline HPMC K4M & 20 & 40 & 60 & - & - & - & - & - & - & - & - & - \\
\hline Sodium Alginate & - & - & - & 20 & 40 & 60 & - & - & - & - & - & - \\
\hline HPMC K 15M & - & - & - & - & - & - & 20 & 40 & 60 & - & - & - \\
\hline Eudragit L 100 & - & - & - & - & - & - & - & - & - & 10 & 22 & 34 \\
\hline Croscarmellose & 144 & 124 & 104 & 144 & 124 & 104 & 144 & 124 & 104 & 154 & 142 & 130 \\
\hline PVP K 30 & 20 & 20 & 20 & 20 & 20 & 20 & 20 & 20 & 20 & 20 & 20 & 20 \\
\hline Magnesium Stearate & 4 & 4 & 4 & 4 & 4 & 4 & 4 & 4 & 4 & 4 & 4 & 4 \\
\hline Talc & 2 & 2 & 2 & 2 & 2 & 2 & 2 & 2 & 2 & 2 & 2 & 2 \\
\hline Iso Propyl Alcohol & Q.S. & Q.S. & Q.S. & Q.S. & Q.S. & Q.S. & Q.S. & Q.S. & Q.S. & Q.S. & Q.S. & Q.S. \\
\hline Total weight & 200 & 200 & 200 & 200 & 200 & 200 & 200 & 200 & 200 & 200 & 200 & 200 \\
\hline
\end{tabular}

Table 1: Composition of Trial Batches of Matrix Tablet of Repaglinide.

\section{Pre Compression Evaluation [7-10].}

\section{Angle of Repose}

To determine angle of repose the granules are allowed to flow freely through funnel on a plain surface. The diameter and height of the heap of the powder is determined $\&$ angle of repose of granules was determined by following equation

$$
\operatorname{Tan} \theta=h / r
$$

Where $\mathrm{h} \& \mathrm{r}$ are height and radius of the powder cone respectively

Bulk Density

Loose bulk density \& Tapped bulk density were determined using the following formulas.
Loose Bulk Density = Weight of Granules / Bulk Volume of Granules

Tapped Bulk Density = Weight of Granules / Tapped Volume of Granules

\section{Compressibility Index}

The compressibility index of the granules was determined by using the following formula.

Carr's Index = Tapped Density - Loose Bulk Density/ Tapped Density* 100

The evaluated pre compression parameters of granules are as shown in Table 2 . 


\begin{tabular}{|c|c|c|c|c|}
\hline Formulations & Bulk Density (g/ml) & Tapped Density (g/ml) & Carr's Index (\%) & Angle of Repose \\
\hline F1 & $0.276 \pm 0.002$ & $0.306 \pm 0.015$ & $6.818 \pm 1.37$ & $24.20 \pm 1.31$ \\
\hline F2 & $0.269 \pm 0.004$ & $0.290 \pm 0.016$ & $10.27 \pm 1.39$ & $26.21 \pm 1.25$ \\
\hline F3 & $0.267 \pm 0.002$ & $0.310 \pm 0.012$ & $7.911 \pm 1.36$ & $27.86 \pm 1.49$ \\
\hline F4 & $0.260 \pm 0.004$ & $0.275 \pm 0.013$ & $12.28 \pm 1.29$ & $26.67 \pm 1.84$ \\
\hline F5 & $0.292 \pm .0004$ & $0.305 \pm 0.010$ & $9.634 \pm 1.34$ & $27.47 \pm 1.72$ \\
\hline F6 & $0.272 \pm 0.005$ & $0.310 \pm 0.014$ & $9.615 \pm 1.37$ & $28.25 \pm 1.56$ \\
\hline F7 & $0.288 \pm 0.005$ & $0.294 \pm 0.011$ & $11.84 \pm 1.31$ & $26.78 \pm 1.54$ \\
\hline F8 & $0.288 \pm 0.004$ & $0.307 \pm 0.014$ & $11.15 \pm 1.34$ & $27.35 \pm 1.79$ \\
\hline F9 & $0.279 \pm 0.004$ & $0.315 \pm 0.010$ & $9.779 \pm 1.35$ & $28.12 \pm 1.64$ \\
\hline F10 & $0.266 \pm 0.003$ & $0.286 \pm 0.014$ & $10.451 \pm 1.37$ & $26.31 \pm 1.54$ \\
\hline F11 & $0.274 \pm 0.002$ & $0.296 \pm 0.015$ & $9.891 \pm 1.25$ & $25.21 \pm 1.47$ \\
\hline F12 & $0.269 \pm 0.005$ & $0.301 \pm 0.011$ & $11.254 \pm 1.34$ & $27.99 \pm 1.35$ \\
\hline
\end{tabular}

Table 2: Pre compression parameters of granules.

Drug-Excipient Compatibility Studies

FTIR Studies: The FT-IR spectrum of pure drug (Repaglinide) and its physical mixture with different grade of polymers and excipients is as shown in figure $1 \&$ 2 and illustrates the compatibility of drug with excipients.
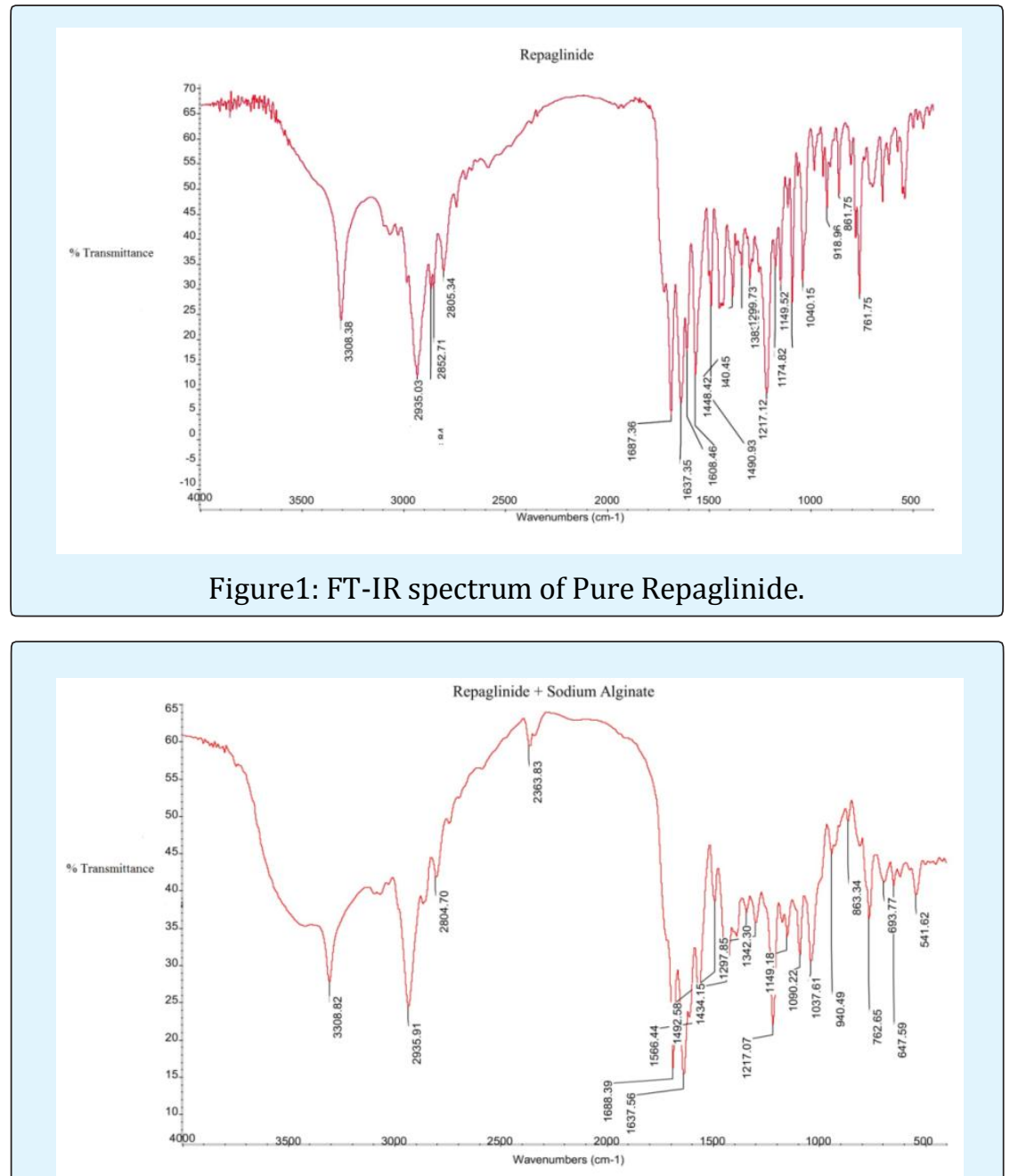

Figure 2: FT IR Spectrum of Repaglinide + Sodium Alginate. 


\section{Bioequivalence \& Bioavailability International Journal}

\section{Post Compression Parameters}

After compression tablets are evaluated for the following parameters $[7,9,10]$.

\section{a. Thickness \& Diameter}

Physical dimensions of the tablet were evaluated by using vernier caliper. It was measured in $\mathrm{mm}$.

\section{b. $\quad$ Appearance \& Texture}

Appearance, color, shapes \& texture of the tablets was evaluated by visual inspection.

\section{c. Hardness}

Hardness of the tablets was evaluated by using Monsanto Hardness Tester \& was expressed in $\mathrm{kg} / \mathrm{cm}^{2}$

\section{d. Friability}

The test was carried out by using Roche fribilator. Pre weighed tablets were introduced into fribilator. The instrument was set at a speed of $25 \mathrm{rpm} \&$ was operated for about 4 minutes. Tablets are weighed again \& \%age weight loss was determined by using following formula. $\%$ age Weight Loss $=(\text { Weight })_{\text {initial }}-(\text { Weight })_{\text {final }} * 100$

\section{e. Weight Variation}

Twenty Tablets were weighed together and average weight was calculated. Then each tablet was weighed individually and means weight was calculated. The \%age difference between the two was calculated. The tablets pass the test if not more than 2 tablets fall outside the percentage limit and none of the tablet should deviate twice of the percentage limit.

\section{f. Drug content uniformity}

20 tablets were weighed and powdered. A quantity equivalent to $100 \mathrm{mg}$ of repaginate was weighed and transferred to $250 \mathrm{ml}$ of volumetric flask. $150 \mathrm{ml}$ of $0.1 \mathrm{~N}$ $\mathrm{HCl}$ was added; shaken well and sonicated for about 2530 minutes. The final volume was made up to $250 \mathrm{ml}$ using $0.1 \mathrm{~N} \mathrm{HCl}$. The solution was filtered and $10 \mathrm{ml}$ of filtrate was taken in volumetric flask. The final volume was made up to $100 \mathrm{ml}$ with $0.1 \mathrm{~N} \mathrm{HCl}$. The absorbance of the resulting solution was measured at $242 \mathrm{~nm}$ using UV Spectrophotometer. The concentration of the drug in the tablet powder was calculated by using the following equation:

$\mathrm{C}_{\mathrm{u}} / \mathrm{C}_{\mathrm{s}}=\mathrm{A}_{\mathrm{u}} / \mathrm{A}_{\mathrm{s}} *$ Dilution Factor

Where $\mathrm{C}_{\mathrm{u}}=$ Concentration of unknown sample

$\mathrm{C}_{\mathrm{s}}=$ Concentration of standard sample

$A_{u}=$ Absorbance of unknown sample

$\mathrm{A}_{\mathrm{s}}=$ Absorbance of standard sample

\begin{tabular}{|c|c|c|c|c|}
\hline Formulations & Thickness (mm) & Hardness $\mathbf{( k g} / \mathbf{c m}^{2}$ ) & Friability (\%) & Drug Content (\%) \\
\hline F1 & $1.79 \pm 0.10$ & $6.3 \pm 0.14$ & $0.35 \pm 0.14$ & 98.22 \\
\hline F2 & $1.75 \pm 0.08$ & $6.5 \pm 0.13$ & $0.30 \pm 0.16$ & 99.54 \\
\hline F3 & $1.92 \pm 0.07$ & $6.2 \pm 0.12$ & $0.26 \pm 0.10$ & 97.21 \\
\hline F4 & $1.89 \pm 0.11$ & $6.0 \pm 0.15$ & $0.31 \pm 0.12$ & 99.61 \\
\hline F5 & $1.95 \pm 0.08$ & $6.1 \pm 0.13$ & $0.32 \pm 0.11$ & 98.51 \\
\hline F6 & $1.86 \pm 0.09$ & $6.3 \pm 0.10$ & $0.29 \pm 0.12$ & 98.95 \\
\hline F7 & $1.94 \pm 0.11$ & $6.2 \pm 0.15$ & $0.30 \pm 0.15$ & 99.34 \\
\hline F8 & $1.76 \pm 0.07$ & $6.5 \pm 0.12$ & $0.27 \pm 0.15$ & 98.12 \\
\hline F9 & $1.90 \pm 0.09$ & $6.1 \pm 0.10$ & $0.33 \pm 0.17$ & 98.64 \\
\hline F10 & $1.85 \pm 0.08$ & $6.0 \pm 0.11$ & $0.28 \pm 0.13$ & 97.62 \\
\hline F11 & $1.92 \pm 0.09$ & $6.2 \pm 0.14$ & $0.31 \pm 0.15$ & 98.14 \\
\hline
\end{tabular}

Table 3: Post Compression evaluation of Repaglinide Sustained Release Tablets.

\section{In- Vitro Dissolution Studies}

In- vitro dissolution studies of the prepared tablets was conducted by using USP Type II Apparatus (Paddle Type) at $37 \pm 0.5{ }^{\circ} \mathrm{C}$. The paddle was rotated at a speed of 50 rpm. The dissolution studies of prepared tablets of repaglinide was carried out first in $0.1 \mathrm{~N} \mathrm{HCl}$ at $\mathrm{pH} 1.2$ for about $2 \mathrm{hrs}$, then these tablets are transferred in phosphate buffer ( $\mathrm{pH} 7.4$ ) and dissolution was carried out. $5 \mathrm{ml}$ of dissolution fluid was withdrawn at regular intervals and filtered through $0.45 \mu \mathrm{m}$ filter paper. Content of drug in each sample was determined by using UV spectrophotometer at $242 \mathrm{~nm}$ for $0.1 \mathrm{~N} \mathrm{HCl} \&$ at 278 $\mathrm{nm}$ for phosphate buffer. The sample withdrawn was replenished with fresh sample after every withdrawal in the dissolution flask. On the basis of the dissolution studies the formulation that gives the best release profile of the drug was considered as the optimized formulation. The dissolution profiles of the different formulations are 


\section{Bioequivalence \& Bioavailability International Journal}

as shown in figure 3-5. On the basis of studies it has been concluded that an increase in the concentration of the

polymer retards the drug release from the matrices.

\begin{tabular}{|c|c|c|c|c|c|c|c|c|c|c|c|c|}
\hline $\mathrm{i} \mathrm{me}$ & $\mathbf{F}$ & $\mathbf{F}$ & $\mathbf{F}$ & $\mathbf{F}$ & $\mathbf{F}$ & $\mathbf{F}$ & $\mathbf{F}$ & $\mathbf{F}$ & $\mathbf{F}$ & F 10 & F 11 & F 12 \\
\hline 0 & 0 & 0 & 0 & 0 & 0 & 0 & 0 & 0 & 0 & 0 & 0 & 0 \\
\hline 1 & 24.21 & 23.75 & 22.20 & 23.21 & 21.24 & 22.94 & 24.24 & 23.57 & 21.41 & 25.21 & 24.98 & 23.68 \\
\hline 2 & 35.21 & 32.21 & 30.22 & 39.67 & 30.20 & 31.69 & 39.65 & 36.24 & 32.76 & 38.51 & 37.65 & 33.12 \\
\hline 3 & 51.21 & 48.46 & 47.21 & 51.24 & 47.21 & 43.69 & 50.85 & 48.36 & 45.25 & 52.11 & 49.54 & 46.15 \\
\hline 4 & 57.25 & 60.25 & 50.86 & 56.64 & 60.48 & 50.48 & 54.34 & 65.86 & 50.35 & 56.21 & .24 & 52.14 \\
\hline 5 & 62.45 & 66.25 & 57.47 & 61.25 & 68.54 & 56.27 & 59.24 & 68.45 & 58.21 & 60.24 & 69.68 & 59.26 \\
\hline 6 & 68.12 & 76.68 & 62.24 & 69.27 & 74.24 & 61.37 & 68.35 & 74.21 & 65.58 & 67.94 & 75.95 & 64.96 \\
\hline 7 & 79.16 & 78.24 & 71.54 & 79.57 & 77.56 & 72.25 & 82.25 & 77.15 & 69.69 & 79.99 & 77.86 & 70.25 \\
\hline 8 & 89.15 & 89.15 & 79.25 & 88.10 & 85.94 & 78.30 & 87.49 & 89.36 & 82.34 & 88.45 & 89.01 & 80.12 \\
\hline 9 & 92.15 & 91.89 & 84.45 & 92.02 & 91.14 & 84.35 & 94.56 & 92.67 & 88.78 & 91.34 & 90.48 & 86.75 \\
\hline 0 & 95.25 & 95.38 & 91.67 & 96.14 & 94.64 & 93.97 & 95.12 & 95.31 & 91.67 & 95.47 & 94.08 & 92.18 \\
\hline 1 & 96.24 & 97.57 & 95.24 & 97.15 & 97.01 & 96.68 & 96.98 & 97.82 & 96.21 & 96.04 & 97.37 & 96.89 \\
\hline 2 & 97.41 & 98.05 & 97.11 & 98.11 & 98.25 & 98.67 & 97.92 & 98.14 & 97.56 & 97.12 & 97.96 & 98.10 \\
\hline
\end{tabular}

Table 4: In-Vitro Dissolution profile of Formulations F1-F12

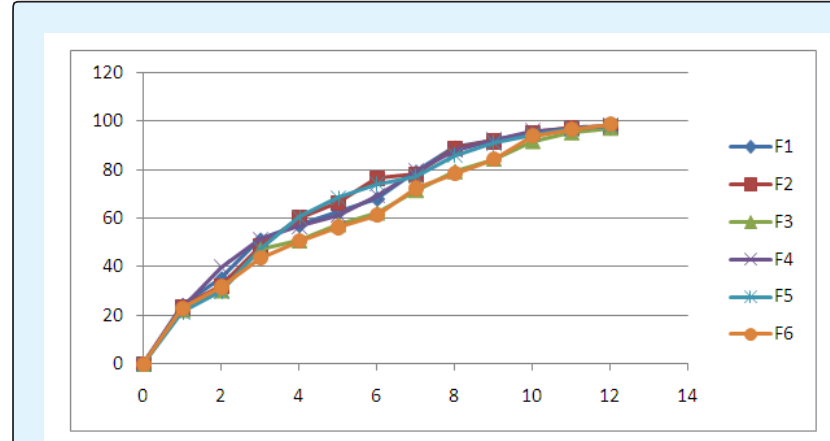

Figure 3: In-Vitro Dissolution Profile of formulation F1-F6.

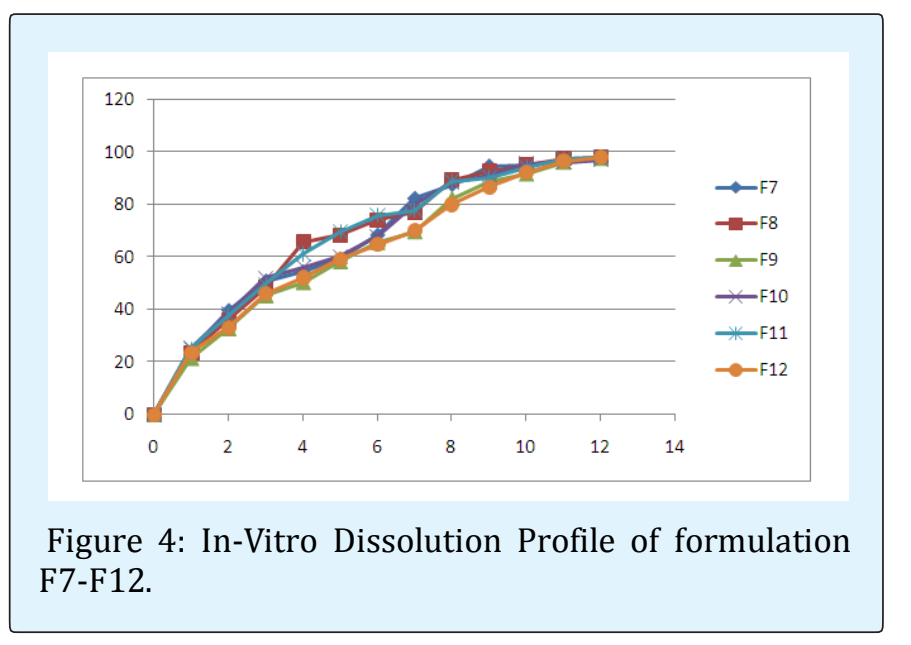

\section{Drug Release Kinetics}

To establish the order and mechanism of drug release, dissolution data of the optimized batches were fitted to four different kinetic models, namely, Zero order model, first order model, Higuchi model and Korsmeyer peppas model. The model for best fit was predicted from the value of $R^{2}$. For an ideal fit, value of $R^{2}$ was 1 . Hence, the model which gives the $\mathrm{R}^{2}$ value nearest to 1 describes the order of drug release.

\begin{tabular}{|c|c|c|c|c|c|}
\hline S.No. & $\begin{array}{c}\text { Time } \\
\text { (hrs) }\end{array}$ & $\begin{array}{c}\text { \%Cumulative Drug } \\
\text { Release ( CDR) }\end{array}$ & $\begin{array}{c}\text { Log \% } \\
\text { CDR }\end{array}$ & (Time) $)^{1 / 2}$ & $\begin{array}{c}\text { Log } \\
\text { Time }\end{array}$ \\
\hline 1 & 0 & 0 & 0 & 0 & 0 \\
\hline 2 & 1 & 22.94 & 1.360 & 1 & 0 \\
\hline 3 & 2 & 31.69 & 1.500 & 1.414 & 0.301 \\
\hline 4 & 3 & 43.69 & 1.640 & 1.732 & 0.477 \\
\hline 5 & 4 & 50.48 & 1.703 & 2.000 & 0.602 \\
\hline 6 & 5 & 56.27 & 1.750 & 2.236 & 0.698 \\
\hline 7 & 6 & 61.37 & 1.787 & 2.449 & 0.778 \\
\hline 8 & 7 & 72.25 & 1.858 & 2.645 & 0.845 \\
\hline 9 & 8 & 78.30 & 1.893 & 2.828 & 0.903 \\
\hline 10 & 9 & 84.35 & 1.926 & 3.000 & 0.954 \\
\hline 11 & 10 & 93.97 & 1.972 & 3.162 & 1 \\
\hline 12 & 11 & 96.68 & 1.985 & 3.316 & 1.041 \\
\hline 13 & 12 & 98.67 & 1.994 & 3.464 & 1.079 \\
\hline
\end{tabular}

Table 5: In-vitro release data of formulation F6: Zero Order Kinetics, First order kinetics, Higuchi model and Korsmeyer peppas model. 

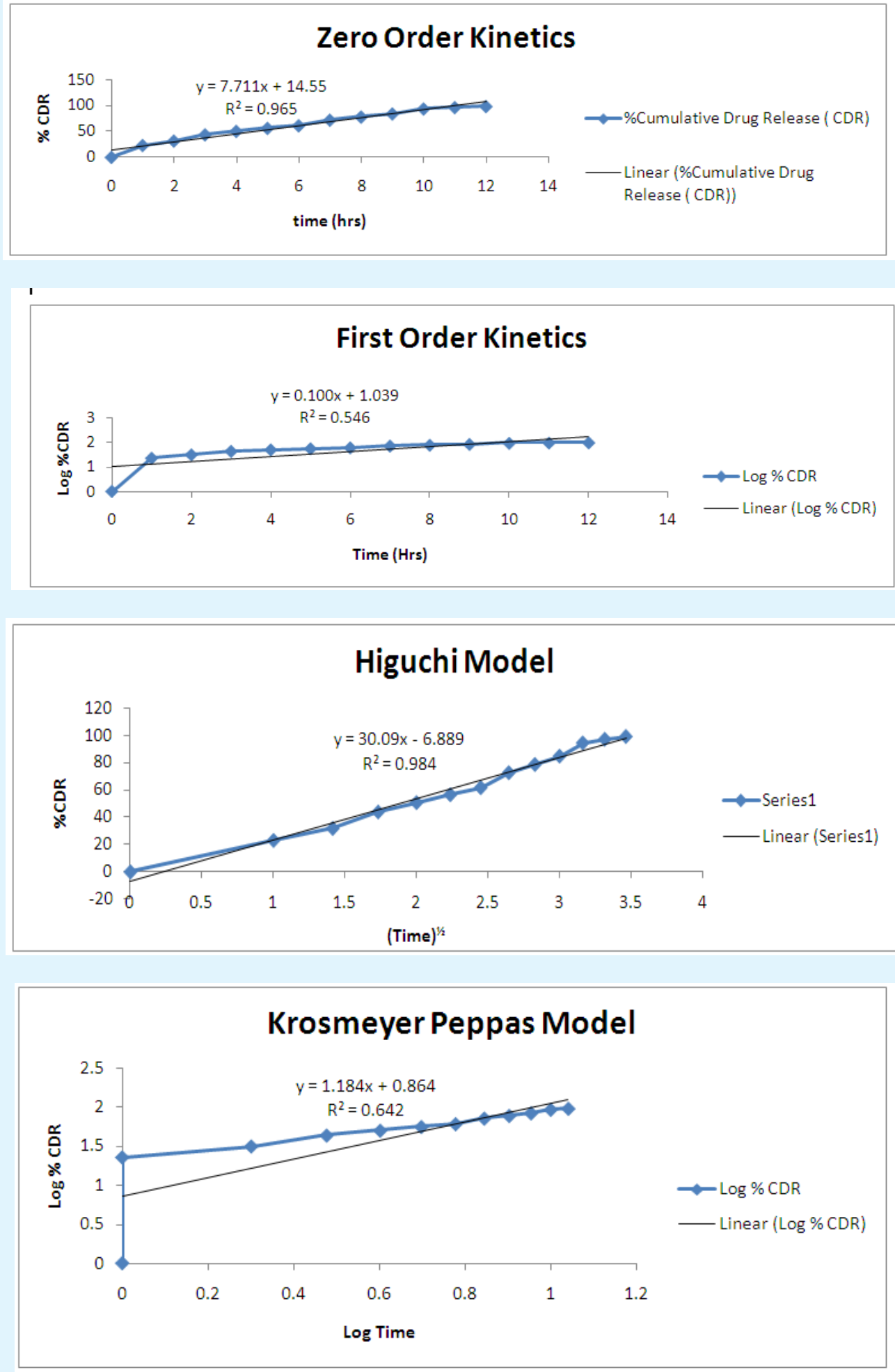

Figure 5: Graphical representation of formulation F6: Zero order Kinetics, First order Kinetics, Higuchi Model \& Korsmeyer peppas model. 


\begin{tabular}{|c|c|c|c|c|}
\hline \multirow{2}{*}{$\begin{array}{c}\text { Formulation } \\
\text { Code }\end{array}$} & $\begin{array}{c}\text { Zero } \\
\text { order }\end{array}$ & $\begin{array}{c}\text { First } \\
\text { order }\end{array}$ & $\begin{array}{c}\text { Higuchi } \\
\text { model }\end{array}$ & $\begin{array}{c}\text { Korsmeyer } \\
\text { Peppas } \\
\text { model }\end{array}$ \\
\hline F6 & 0.965 & 0.546 & 0.984 & 0.642 \\
\hline
\end{tabular}

Table 6: Value of $\mathrm{R}^{2}$ obtained from different kinetic models.

From the results of data fitting to various models (table 6), it was found that the optimized batch F6 showed zero order drug release \& followed Higuchi model describing drug release from polymeric matrix.

\section{Results \& Discussion}

The aim of present project is formulation, development \& evaluation of sustained release matrix tablet of Repaglinide $200 \mathrm{mg}$. The SR tablets of repaglinide were prepared by wet granulation method using non aqueous solvent Iso Propyl alcohol. Extended release was achieved by using the polymers like HPMC K4M, HPMC K15M, Sodium alginate, Eudragit L100 \& Croscarmellose. FTIR Spectra of the drug polymer spectra shows compatibility Total 12 trial batches of sustained release matrix tablets containing different concentrations of polymers were prepared. All the tablets were prepared under similar conditions to avoid processing variables. For each designed formulation, granules blend of drug and excipients were prepared and evaluated for micromeritic properties like bulk density, tapped density, Carr's index. The sustained release matrix tablet of Repaglinide were evaluated for their general appearance, physical parameters like thickness, hardness, weight variation, friability, drug content, In-vitro drug release. The above mentioned tests were performed using official procedures. The sample of Repaglinide was analyzed by various organoleptic, physicochemical and spectro photo metric methods. The sample of repaglinide possessed similar odor, color \& taste as given in officials. Repaglinide sustained release matrix tablets were successfully prepared by using various grades of HPMC as polymer to retard the release and achieve the retard dissolution profile. Drug \& polymer were found to be compatible as indicated by FTIR studies.

Matrix tablets of repaglinide were prepared by wet granulation technique. The granules possessed satisfactory flow properties. All the tablet formulations showed acceptable properties \& complied with I.P. specifications for weight variation, drug content uniformity, hardness, friability.
- The granules showed Carr's index ranging from 6.81812.28 \& angle of repose in range of 24.20-28.25.

- All the formulations showed good blend properties for wet granulation and hence tablets were prepared by using wet granulation method.

- The tablets prepared were found to be good without any defects like chipping, capping \& sticking.

- Post compression parameters of the tablet formulations were found to be satisfactory and within permissible range.

- Drug content was in range of 97.15 to 99.61 . The values of result reveal that tablet holds good handling \& transportation properties as well as sufficient active drug content.

It was found that drug release from the matrix tablets was decreased with increase in drug polymer ratio. Release rate of the drug from the matrix was significantly influenced by proportion of swelling of polymer. The matrix tablets of formulations F1 to F3 consist of HPMC K $4 \mathrm{M}$ as polymer. The release rate of the formulation was in order $\mathrm{F} 1>\mathrm{F} 2>\mathrm{F} 3$ up to $3 \mathrm{hrs}$ then $\mathrm{F} 2>\mathrm{F} 1>\mathrm{F} 3$ up to $10-11$ hrs. The release rate of formulation F3 was 97.11 at an interval of $12 \mathrm{hrs} \&$ of formulation F2 was found to be 98.05 at $12 \mathrm{hrs}$. The order of drug release for formulation F4 to F6 containing polymer sodium alginate was found to be $\mathrm{F} 4>\mathrm{F} 5>\mathrm{F} 6$ up to $3 \mathrm{hrs}$, then F5>F4>F6 up to $11 \mathrm{hrs}$. The release rate of formulation F6 was found to be 98.67 \& of formulation F5 was found to be 98.25 at $12 \mathrm{hrs}$.

For formulations F7 - F9 containing polymer HPMC K $15 \mathrm{M}$ the order of drug release was found to be $\mathrm{F} 7>\mathrm{F} 8>\mathrm{F} 9$ up to 3hrs. Then F8>F7>F9 up to 10 hrs: F9>F8>F7 for 11-12 hrs. The release rate of formulation F9 at $12 \mathrm{hrs}$ was found to be 97.56. For formulations F10-F12 containing polymer Eudragit L100 the order of drug release was found to be F10 $>$ F11 $>$ F12 for 3hrs, then F11 $>$ F110 $>$ F12 up to $10 \mathrm{hrs}$; then F12>F11>F10 for 11-12 hrs. The release rate of formulation F12 at $12 \mathrm{hrs}$ was found to be 98.10 . The formulation $\mathrm{F} 6$ shows most significant result in terms of sustained release \& in-vitro dissolution rate. Thus Formulations F4-F6 containing polymer Sodium alginate was found to be the best one. It may be concluded from the present study that slow \& controlled release of repaglinide over a period of $12 \mathrm{hrs}$ was obtained from formulation F6 using polymer sodium alginate. The drug release kinetics revealed zero order release pattern \& follows higuchi model. Formulation \& evaluation of SR matrix tablet of repaglinide was fond to be satisfactory. On the basis of various evaluated parameters the formulation F6 shows most significant result in terms of sustained release \& in-vitro dissolution rate. Thus 


\section{Bioequivalence \& Bioavailability International Journal}

Formulations F4-F6 containing polymer Sodium alginate was found to be the best one.

\section{Conclusion}

Repaglinide sustained release matrix tablets were successfully prepared by using various grades of HPMC, Eudragit L100 \& Sodium alginate as polymer to retard the release and achieve the retarded dissolution profile. Drug \& polymer were found to be compatible as indicated by FTIR studies. From the observations it was concluded that polymers used in different concentrations differ in their ability to sustain the drug release. Further it was concluded that polymer Sodium alginate showed better extended release property than HPMC K4M, HPMC K15M \& Eudragit L100 used in formulation of sustained release matrix tablet. It was found that drug release from the matrix tablets was decreased with increase in drug polymer ratio. Release rate of the drug from the matrix was significantly influenced by proportion of swelling of polymer. It may be concluded from the present study that slow \& controlled release of repaginate over a period of $12 \mathrm{hrs}$ was obtained from formulation F6 using polymer Sodium alginate. The drug release kinetics revealed zero order release pattern \& followed higuchi model. Formulation \& in-vitro evaluation of SR matrix tablet of repaglinide was found to be satisfactory. On the basis of various evaluated parameters formulation F6 was considered to be the best one.

The results of release studies indicated the possibility of achieving a suitable modulation of repaglinide by varying the concentrations of polymers (Eudragit L100, HPMC K4M, K15M, and Sodium Alginate) in the tablet \& could lead the market with respect to their counterparts.

\section{References}

1. Reddy DV, Rao AS (2014) Formulation and evaluation of extended release tablets of Tapentadol hydrochloride using hydrophilic-hydrophobic polymer combinations. J Pharma Res. 8(10): 13681374.
2. Kumar V, Prajapati SK, Soni GC, et al. (2012) Sustained release matrix type drug delivery system: a review. World Journal of Pharmacy and Pharmaceutical Sciences 1(3): 934-960.

3. Maderuelo C, Zarzuelo A, Lanao JM (2011) Critical factors in the release of drugs from sustained release hydrophilic matrices. J Control Release 154(1): 2-19.

4. American Diabetes Association (2004) Diagnosis and classification of diabetes mellitus. Diabetes care. 27(1): s5-s10.

5. Ambavane V, Patil R, Ainapure SS (2002) Repaglinide: a short acting insulin secretagogue for postprandial hyperglycemia. Journal of postgraduate medicine 48(3): 246-248.

6. Owens DR (1998) Repaglinide-prandial glucose regulator: a new class of oral antidiabetic drugs. Diabetic medicine 15(S4): S28-S36.

7. Arakeri V, Kumar PA, Kulkarni SV (2014) Design and In-Vitro evaluation of sustained release matrix tablets of Repaglinide. International Journal for Pharmaceutical Research Scholars 3(4): 142-153.

8. Joshi J, Bhakuni L, Kumar S (2012) Formulation and evaluation of solid matrix tablets of Repaglinide. Der. Pharm. Sin 3(5): 598-603.

9. Barot N, Darshan M, Praful DB (2014) Formulation development and evaluation of sustained release matrix tablets of repaglinide. International Journal of Pharmaceutical Research and Bio-Science 3(2): 370396.

10. Sarfaraz MD, LingarReddy B, Rajagopal UH (2013) Design and in vitro evaluation of gastro retentive floating tablets of Repaglinide. International Journal of drug delivery \& research 5(3): 322-332. 